\title{
Aqueous Solubility Enhancement of Mirtazapine: Effect of Cosolvent and Surfactant
}

\author{
Kenneth E. Ezealisiji ${ }^{1}$, Chika J. Mbah ${ }^{2 *}$, Patience 0. Osadebe ${ }^{2}$ \\ ${ }^{1}$ Department of Pharmaceutical Chemistry, Faculty of Pharmaceutical Sciences, University of Port Harcourt, \\ Port Harcourt, Nigeria \\ ${ }^{2}$ Department of Pharmaceutical and Medicinal Chemistry, Faculty of Pharmaceutical Sciences, University of Ni- \\ geria, Nsukka, Nigeria \\ Email: ${ }^{*}$ cjmbah123@yahoo.com
}

Received 28 July 2015; accepted 20 October 2015; published 23 October 2015

Copyright (C) 2015 by authors and Scientific Research Publishing Inc.

This work is licensed under the Creative Commons Attribution International License (CC BY).

http://creativecommons.org/licenses/by/4.0/

Open Access

\begin{abstract}
The poor aqueous solubility of drugs is a challenging problem faced by pharmaceutical scientists in drug formulation. Cosolvency and micellization techniques have been severally used to enhance the solubility of poorly aqueous soluble drugs. Mirtazapine, a tetracyclic antidepressant used for the treatment of moderate to severe depression and anxiety, has very poor aqueous solubility. The objective of the study was to investigate the effect of solubilizing agents (cosolvents and surfactants) on the aqueous solubility of mirtazapine while envisaging that any significant improvement in its aqueous solubility could contribute towards alleviating the withdrawal symptoms often associated with the drug. The solubility of mirtazapine was determined at room temperature in aqueous mixtures of cosolvents (propylene glycol and polyethylene glycol 400) and surfactants (polysorbate 20, polysorbate 80 and sodium lauryl sulfate). An exponential increase in mirtazapine solubility was observed when total drug solubility in water-cosolvent system was plotted against cosolvent fraction volume. Polyethylene glycol 400 gave larger solubilization capacity $(\sigma)$ when compared to propylene glycol. With the surfactants, linear relationship between the total solubility of the drug in water-surfactant mixtures and surfactant concentration was noted. Sodium lauryl sulfate showed the largest solubilization power $(k)$ when compared to the nonionic surfactants (polysorbate 20 and polysorbate 80 respectively). A linear relationship between standard free energy and partition coefficient was also observed. The result of the study shows that aqueous solubility of mirtazapine is significantly improved by cosolvency and micellization and therefore there exists the possibility of improving the withdrawal symptoms often experienced with the drug. It also suggests that large free energy is required for drugs with high partition coefficients to permeate the biological membrane.
\end{abstract}

${ }^{*}$ Corresponding author. 


\section{Keywords}

\section{Mirtazapine, Cosolvency, Micellization, Aqueous Solubility}

\section{Introduction}

Mirtazapine, [ \pm ]-2-methyl-1,2,3,4,10,14b-hexahydropyrazino[2,1-a]pyrido[2,3-e] benzazopine, whose chemical structure is presented in Figure 1, is a tetracyclic antidepressant drug that exists as enantiomers and both enantiomers contribute to the antidepressant activity. Clinically, mirtazapine is used for the treatment of moderate to severe depression and anxiety. Its mechanism of action involves 1$)$ antagonism at postsynaptic $5-\mathrm{HT}_{2}[\mathrm{~S}(+)$ enantiomer] and 5- $\mathrm{HT}_{3}[\mathrm{R}(-)$ enantiomer] receptors thereby enhancing serotoninergic neurotransmission which is specifically mediated via $5-\mathrm{HT}_{1}$ receptors; 2) antagonism at centrally active presynaptic $\alpha-2$ receptor, which increases noradrenergic and serotoninergic neurotransmission; 3) antagonism at histamine $\mathrm{H}_{1}$-receptor but has practically no anticholinergic activity [1]-[3].

Mirtazapine is available only as tablets in doses of $15 \mathrm{mg}, 30 \mathrm{mg}$, and $45 \mathrm{mg}$ respectively [4]. Mirtazapine is practically insoluble in water and its logarithm partition coefficient (octanol-water) is 2.9, indicating high hydrophobicity. Due to potential withdrawal symptoms, such as diarrhea, nausea, anxiety, aggression, irritability, internal restlessness, hostility, deep depression etc., that occur during therapy with mirtazapine, the drug does not belong to the first line of antidepressants. These withdrawal symptoms could arise due to its very poor water solubility and high lipophilicity. The pharmacokinetics of mirtazapine indicates that the drug has average bioavailability (50\%), high protein binding (85\%) and very high half-life (20 - 40 h). It was therefore envisaged that enhancement of aqueous solubility of mirtazapine could lead to improvement in its bioavailability, reduction in protein binding and half-life and invariably a decrease in its withdrawal symptoms. A number of technological methods such as chemical modification, cosolvency, cyclodextrin complexation, micellization, microemulsion, micronization, mucoadhesive microspheres, nanoemulsion, nanoparticles, nanosuspensions, self-emulsifying systems and solid dispersion have been used to enhance the solubility of poorly aqueous soluble drugs [5]-[8]. Therefore, the present study was aimed at using cosolvency, micellization to enhance the aqueous solubility of mirtazapine. Cosolvency (mixing a permissible non-toxic organic solvent with water) is the most common and feasible technique to enhance the aqueous solubility of drugs. The common cosolvents utilized are glycerin, ethanol, polyethylene glycols (mainly 200, 300 and 400), polyethylene glycol ether, propylene glycol and tetrahydrofurfuryl alcohol [9]-[11]. Surfactants (amphiphilic molecules composed of a hydrophilic moiety known as the head and a hydrophobic moiety known as the tail) have been reported to solubilize a number of poorly water soluble drugs [12]-[16]. They do that by forming colloidal clusters in solutions called micelles. As association colloids, micelles can form spontaneously under certain conditions (self assembling system) and are thermodynamically more stable towards both dissociation and aggregation [17]. Literature review has revealed that mirtazapine is practically insoluble in water and that no study on the enhancement of the drug's aqueous solubility by cosolvency and micellization has been reported. Therefore, we took to investigate the extent to which the aqueous solubility of mirtazapine could be enhanced by cosolvents (propylene glycol, polyethylene glycol 400) and surfactants (sodium lauryl sulfate, polysorbate 20, polysorbate 80 ) while envisaging that the aqueous solubility enhancement could potentially alleviate the drug problems that contribute to its withdrawal symptoms.

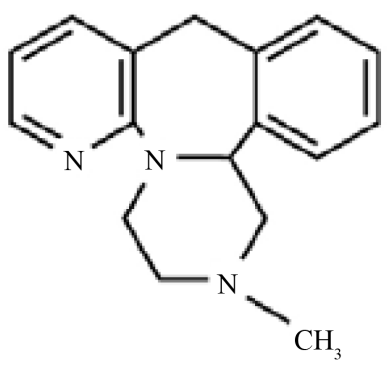

Figure 1. Chemical structure of mirtazapine. 


\section{Materials and Methods}

The materials including mirtazapine (Mylan Pharmaceuticals, USA), propylene glycol, polysorbate-20, polysorbate-80 and sodium lauryl sulfate (Sigma-Aldrich, USA), chloroform (Fisher Scientific, USA) and other chemicals were of analytical reagent grade.

\section{Solubility Measurement}

The mirtazapine powder was added to vials containing various percentages of cosolvents or surfactants. The vials were capped and shaken on mechanical shaker $(25 \mathrm{rpm})$ for $24 \mathrm{~h}$ at $25^{\circ} \mathrm{C}$. Samples with drug crystals present were considered to have reached equilibrium (no further increase in dissolved drug concentration was observed after $12 \mathrm{~h}$ ). The samples were then filtered through $0.45 \mu \mathrm{m}$ filter and the supernatant (drug aqueous solution, drug cosolvent solution, drug micellar solution respectively) were analyzed using UV/Vis spectrophotometric method (Perkin Elmer Lambda 35 UV-Vis spectrophotometer) at a wavelength of $290 \mathrm{~nm}$. Determination was done in triplicate.

\section{Results and Discussion}

The solubility of mirtazapine in water, cosolvents and surfactants at $25^{\circ} \mathrm{C}$ is provided in Table 1 .

The results show that the drug exhibits very poor water solubility probably because of its inability to effectively break into the lattice structure of water. With the cosolvents, polyethylene glycol 400 gave greater solubility enhancement than propylene glycol. For instance, at the highest concentration studied $(50 \% \mathrm{w} / \mathrm{v})$, the aqueous solubility of mirtazapine were 0.0512 and $0.0619 \mathrm{mg} / \mathrm{ml}$ for propylene glycol and polyethylene glycol 400 respectively. At the same concentration polyethylene glycol 400 gave 33-fold increase in the aqueous solubility of the drug. Such observation could be attributed to the nonpolar hydrocarbon region in the polyethylene glycol 400 showing greater tendency to reduce the ability of the aqueous system to squeeze out mirtazapine when compared to the nonpolar hydrocarbon region of propylene glycol. A plot of the total solubility of the drug versus cosolvent concentration is shown in Figure 2.

The figure shows the exponential increase in mirtazapine solubility with concentration of the cosolvent. The logarithmic relationship between total drug solubility $\left(S_{\text {tot }}\right)$ in a mixed solvent and cosolvent concentration $\left(C_{\text {cosol }}\right)$ can be described by Equation (1) [18] [19].

$$
\log S_{\text {tot }}=\log S_{w}+\sigma C_{\text {colsol }}
$$

where $S_{\text {tot }}$ is total drug solubility, $S_{w}$ is drug solubility in water and $\sigma$ is cosolvent solubilization power. The result of the solubilization of mirtazapine by surfactants is also given in Table 1. Of the surfactants investigated, sodium lauryl sulfate produced the greatest enhancement in the aqueous solubility of mirtazapine. A 44-fold increase in the aqueous solubility of the drug was observed. The increase could arise from the micellar effect

Table 1. Effect of propylene glycol, polyethylene glycol 400, sodium lauryl sulfate, polysorbate 20 and polysorbate 80 on the aqueous solubility of mirtazapine.

\begin{tabular}{|c|c|c|c|c|c|c|}
\hline \multirow{2}{*}{$\begin{array}{c}\text { Concentration } \\
\text { of Cosolvent } \\
(\% \mathrm{w} / \mathrm{v})\end{array}$} & \multicolumn{2}{|c|}{${ }^{\mathrm{a}}$ Solubility (mg/ml) } & \multirow{2}{*}{$\begin{array}{l}\text { Surfactant } \\
\text { Conc. } \\
(\% \mathrm{w} / \mathrm{v})\end{array}$} & \multicolumn{3}{|c|}{ as Solubility (mg/ml) } \\
\hline & Propylene glycol & $\begin{array}{l}\text { Propylene glycol } \\
400\end{array}$ & & Polysorbate 20 & Polysorbate 80 & $\begin{array}{l}\text { Sodium lauryl } \\
\text { sulfate }\end{array}$ \\
\hline 0.00 & $0.00186 \pm 0.0012$ & $0.00186 \pm 0.0012$ & 0.00 & $0.00186 \pm 0.0012$ & $0.00186 \pm 0.0012$ & $0.00186 \pm 0.0012$ \\
\hline 5.00 & $0.01087 \pm 0.0011$ & $0.01323 \pm 0.0007$ & 0.05 & $0.00743 \pm 0.0005$ & $0.01069 \pm 0.0011$ & $0.01293 \pm 0.0006$ \\
\hline 10.0 & $0.01674 \pm 0.0006$ & $0.02082 \pm 0.0016$ & 0.10 & $0.01302 \pm 0.0006$ & $0.01653 \pm 0.0013$ & $0.02114 \pm 0.0012$ \\
\hline 15.0 & $0.02003 \pm 0.0008$ & $0.02448 \pm 0.0013$ & 0.20 & $0.01562 \pm 0.0007$ & $0.02072 \pm 0.0011$ & $0.02521 \pm 0.0004$ \\
\hline 20.0 & $0.02331 \pm 0.0004$ & $0.02813 \pm 0.0008$ & 0.50 & $0.02046 \pm 0.0009$ & $0.02678 \pm 0.0006$ & $0.03441 \pm 0.0006$ \\
\hline 25.0 & $0.02663 \pm 0.0012$ & $0.03179 \pm 0.0019$ & 1.00 & $0.03088 \pm 0.0012$ & $0.04222 \pm 0.0017$ & $0.05089 \pm 0.0011$ \\
\hline 30.0 & $0.03151 \pm 0.0009$ & $0.03781 \pm 0.0012$ & 2.00 & $0.05172 \pm 0.0018$ & $0.07142 \pm 0.0013$ & $0.08251 \pm 0.0016$ \\
\hline 50.0 & $0.05115 \pm 0.0008$ & $0.06187 \pm 0.0017$ & & & & \\
\hline
\end{tabular}

$\mathrm{a}=$ Mean $\pm \mathrm{SD}$, where SD = standard deviation, $(\mathrm{n}=3)$. 
rather than its alkaline property since mirtazapine was a neutral drug. Polysorbate 80 (tween 80) gave higher solubilization of the drug than polysorbate 20 (tween 20) probably due to its longer alkyl chains. Figure 3 depicts a plot of the total solubility of the drug versus surfactant concentration.

Linear relationship between the total solubility of the drug in water-surfactant mixtures and surfactant concentration was observed. The relationship between the drug solubility in a micellar solution and surfactant concentration can be explained by Equation (2) [20].

$$
S_{\text {tot }}=S_{w}+k C_{\text {surf }}
$$

where $C_{\text {surf }}$ is the concentration of micellar surfactant (i.e., the total surfactant concentration minus the critical micellar concentration) and $k$ is the molar solubilization capacity (the number of moles of solute that can be solubilized by 1 mole of micellar surfactant). Equation (2) indicates that the critical micellar concentration (cmc) is much lower than $C_{\text {surf. }}$. The overall enhancement in the aqueous solubility of mirtazapine by the surfactants could be described by two descriptors, namely molar solubilization capacity $k$ and the micelle-water partition coefficient, $P$. The molar solubilization capacity $k$ is obtained from the slope of a plot of the total solubility of the drug versus surfactant concentration or by using Equation (3).

$$
k=\frac{S_{\text {tot }}-S_{w}}{C_{\text {surf }}}
$$

The regression equations describing the micellar solubilization are: $S_{\text {tot }}=0.0212 C_{\text {surf }}+0.0096$;

$S_{\text {tot }}=0.0212 C_{\text {surf }}+0.0124$ and $S_{\text {tot }}=0.0336 C_{\text {surf }}+0.0163$ for polysorbate 20 , polysorbate 80 and sodium lauryl surfate respectively.

The micelle-water partition coefficient is defined as the ratio of the amount of drug in water to the amount of drug in micelle and is represented by Equation (4)

$$
P=\frac{S_{t o t}-S_{w}}{S_{w}}
$$

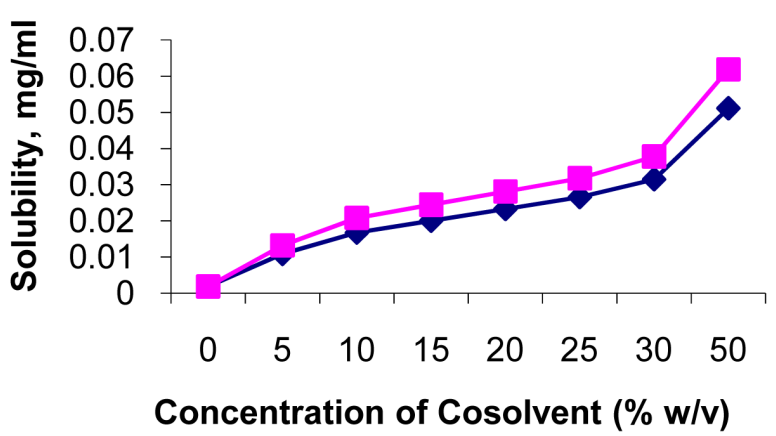

Figure 2. Plot of solubility versus concentration of cosolvent, $\square------\square$ : Polyethylene glycol 400; $\square------\square$ : Propylene glycol.

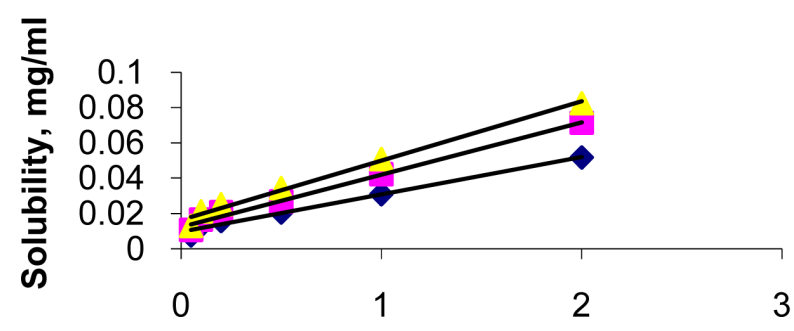

Concentration of Surfactant $(\% \mathrm{w} / \mathrm{v})$

Figure 3. Plot of Solubility versus concentration of surfactant. $\Delta$------- $\Delta$ : Sodium lauryl sulfate; $\square--------\square$ : Polysorbate 80; $\square---------\square$ : Polysorbate 20. 
Equation (4) is used to calculate the partition coefficient of mirtazapine in the micellar solutions and the results are shown in Table 2.

As micellar solubilization is a thermodynamic process, we considere it necessary to ascertain the standard free energy $\left(\Delta G^{o}\right)$ of micellar solubilization using Equation (5) [21] and correlate it with the partition coefficient (PC).

$$
\Delta G^{o}=-R T \ln P
$$

The negative values obtained for the standard free energy (Table 2) are indicative of the spontaneity of the solubilization process. In order to correlate the two parameters, the partition coefficient was plotted against the standard free energy (ignoring the negative sign). A linear relationship was observed with the correlation coefficient $\left(R^{2}\right)$ of $0.8947,0.9181$ and 0.9332 for polysorbate 20, polysorbate 80 and sodium lauryl sulfate respectively.

In Figure 4 we used sodium lauryl sulfate data to illustrate the plot of standard free energy versus partition coefficient $(r=0.9332)$.

\section{Conclusion}

These vehicles investigated are generally considered safe for oral administration [22]-[24]. Although mirtazapine is very poorly soluble in water, its solubility is observed to be significantly enhanced by cosolvency and micellization. The enhanced aqueous solubility of the drug implies potential improvement on the drug properties such as bioavailability, protein binding and half-life which could probably lead to reduction in the withdrawal symptoms associated with the drug. The study is able to establish a linear relationship between standard free energy and the partition coefficient of the drug in micellar solution implying that large free energy is required for drugs with high partition coefficients to permeate the biological membrane. None of the vehicles investigated is able to produce the minimum drug solubility that is required for $5-\mathrm{ml}$ or 2 -ml dose of the smallest unit

\section{Table 2. Solubilization Parameters (micelle-water partition coefficient and standard free energy of micellar solubilization).}

\begin{tabular}{|c|c|c|c|c|c|c|}
\hline \multirow{2}{*}{$\begin{array}{c}\text { Concentration of } \\
\text { surfactant }(\% \mathrm{w} / \mathrm{v})\end{array}$} & \multicolumn{2}{|c|}{ Polysorbate-20 } & \multicolumn{2}{|c|}{ Polysorbate-80 } & \multicolumn{2}{|c|}{ Sodium lauryl sulfate } \\
\hline & PC & $\Delta \mathrm{G}^{\mathrm{o}}$ & PC & $\Delta \mathrm{G}^{\mathrm{o}}$ & PC & $\Delta \mathrm{G}^{\mathrm{o}}$ \\
\hline 0.00 & - & - & - & - & - & - \\
\hline 0.05 & 2.995 & -2718.08 & 4.747 & -3859.78 & 6.919 & -4793.37 \\
\hline 0.10 & 6.000 & -4440.28 & 7.887 & -5117.95 & 10.366 & -5795.17 \\
\hline 0.20 & 7.398 & -4959.26 & 10.140 & -5740.59 & 12.554 & -6269.80 \\
\hline 0.50 & 10.000 & -5706.19 & 13.398 & -6431.07 & 17.500 & -7093.01 \\
\hline 1.00 & 15.602 & -6808.05 & 21.699 & -7625.97 & 26.360 & -8108.20 \\
\hline 2.00 & 26.807 & -8149.81 & 37.398 & -8974.96 & 43.360 & -9341.53 \\
\hline
\end{tabular}

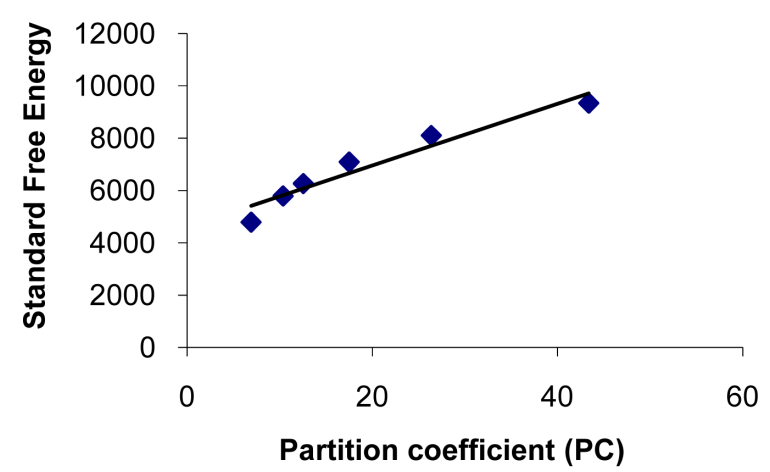

Figure 4. Plot of standard free energy $\left(\Delta \mathrm{G}^{0}\right)$ versus partition coefficient (PC). 
dose (15 mg) of the drug. The result, therefore, suggests that the studied vehicles are not applicable to formulate oral liquid or parenteral dosage forms of mirtazapine, but could be incorporated into solid dosage forms (tablets or capsules) as excipients.

\section{References}

[1] Nakayama, K., Sakurai, T. and Katsu, H. (2004) Mirtazapine Increases Dopamine Release in Prefrontal Cortex by 5-HT $\mathrm{HA}_{\mathrm{A}}$ Receptor Activation. Brain Research Bulletin, 63, 237-241. http://dx.doi.org/10.1016/j.brainresbull.2004.02.007

[2] Peter, M. and Hartmann, S. (1999) Mirtazapine: A Newer Antidepressant. American Family Physician, 59, $159-161$.

[3] de Boer, T. (1996) The Pharmacology Profile of Mirtazapine. Journal of Clinical Psychiatry, 57, 19-25.

[4] (2005) Physcian Desk Reference. 59th Edition, Thomson PDR, New Jersey, 2216.

[5] Shafiq, S., Shakeel, F., Talegaonkar, S., Ahmed, F.J., Khar, R.K. and Ali, M. (2007) Development and Bioavailability Assessment of Ramipril Nanoemulsion Formulation. European Journal of Pharmaceutics and Biopharmaceutics, 66, 227-243. http://dx.doi.org/10.1016/j.ejpb.2006.10.014

[6] Lee, P.J., Lenger, R. and Shestri, V.P. (2003) Novel Microemulsion Enhancer Formulation for Simultaneous Transdermal Delivery of Hydrophilic and Hydrophobic Drugs. Pharmaceutical Research, 20, 264-269. http://dx.doi.org/10.1023/A:1022283423116

[7] Mbah, C.J. (2006) Solubilization of Valsartan by Aqueous Glycerol, Polyethylene Glycol and Micellar Solutions. Die Pharmazie, 61, 322-324.

[8] Li, P., Zhao, L.W. and Yalkowsky, S.H. (1999) Combined Effect of Cosolvent and Cyclodextrin on Solubilization of Non-Polar Drugs. Journal of Pharmaceutical Sciences, 88, 1107-1111. http://dx.doi.org/10.1021/js990159d

[9] Yalkowsky, S.H. and Roseman, T.J. (1981) Solubilization of Drugs by Co-Solvents. In: Yalkowsky, S.H., Ed., Techniques of Solubilization of Drugs, Vol. 12, Marcel Dekker Inc., New York, 91-134.

[10] Yalkowsky, S.H. and Rubino, J.T. (1985) Solubilization of Cosolvents 1: Organic Solutes in Propylene Glycol-Water Mixtures. Journal of Pharmaceutical Sciences, 74, 416-421. http://dx.doi.org/10.1002/jps.2600740410

[11] Seedher, N. and Kaur, J. (2003) Solubilization of Nimesulide: Use of Co-Solvents. Indian Journal of Pharmaceutical Sciences, 65, 58-61.

[12] Krishn, A.K. and Flanagan, D.R. (1989) Micellar Solubilization of a New Antimalarial Drug, $\beta$-Arteether. Journal of Pharmaceutical Sciences, 78, 574-576. http://dx.doi.org/10.1002/jps.2600780713

[13] Zhao, L., Li, P. and Yalkowsky, S.H. (1999) Solubilization of Fluasterone. Journal of Pharmaceutical Sciences, 88, 967-969. http://dx.doi.org/10.1021/js9901413

[14] Li, P. and Zhao, L. (2003) Solubilization of Flurbiprofen in pH-Surfactant Solutions. Journal of Pharmaceutical Sciences, 92, 951-956. http://dx.doi.org/10.1002/jps.10360

[15] Alkhamis, K.A., Allaboun, H. and Al-Momani, W.Y. (2003) Study of the Solubilization of Gliclazide by Aqueous Micellar Solutions. Journal of Pharmaceutical Sciences, 92, 839-846. http://dx.doi.org/10.1002/jps.10350

[16] Seedher, N. and Kanojia, M. (2008) Micellar Solubilization of Some Poorly Soluble Antidiabetic Drugs. AAPS Pharm SciTech, 9, 431-436. http://dx.doi.org/10.1208/s12249-008-9057-5

[17] Hunter, R.J. (1993) Introduction to Modern Colloid Science. Oxford University Press, Oxford.

[18] Zhao, L., Li, P. and Yalkowsky, S.H. (1999) Solubilization of Fluasterone. Journal of Pharmaceutical Sciences, 88, 967-969. http://dx.doi.org/10.1021/js9901413

[19] Ran, Y., Zhao, L., Xu, Q. and Yalkowsky, H. (2001) Solubilization of Cyclosporin A. AAPS PharmSciTech, 2, 23-26. http://dx.doi.org/10.1208/pt020102

[20] Ong, J.T.H. and Manoukian, E. (1988) Micellar Solubilization of Timbesone Acetate in Aqueous and Aqueous Propylene Glycol Solutions of Nonionic Surfactants. Pharmaceutical Research, 3, 704-708. http://dx.doi.org/10.1023/A:1015903827042

[21] Rangel-Yagui, C.O., Junior, A.P. and Tavares, L.C. (2005) Micellar Solubilization of Drugs. Journal of Pharmaceutical Sciences, 8, 147-163.

[22] Sweetana, S. and Akers, M.J. (1996) Solubility Principles and Practices for Parenteral Drug Dosage form Development. PDA Journal of Pharmaceutical Science and Technology, 50, 50-56.

[23] Powell, M.J., Nguyen, T. and Baloian, L. (1998) Compendium of Excipients for Parenteral Formulations. PDA Journal of Pharmaceutical Science and Technology, 52, 238-311.

[24] Mottu, F., Laurent, A., Rufenacht, D. and Doelker, E. (2000) Organic Solvents for Pharmaceutical Parenterals and Embolic Liquids: A Review of Toxicity Data. PDA Journal of Pharmaceutical Science and Technology, 54, 456-469. 